\title{
Padrões de uso do tempo por novilhos em pastagem consorciada de azevém anual e aveia-preta ${ }^{1}$
}

\author{
Carolina Baggio 2 , Paulo César de Faccio Carvalho ${ }^{3}$, Jamir Luís Silva da Silva ${ }^{3}$, Lemar \\ Maciel da Rocha ${ }^{2}$, Carolina Bremm², Davi Teixeira dos Santos², Alda Lucia Gomes Monteiro4 \\ ${ }^{1}$ Projeto financiado pelo CNPq. \\ 2 Programa de Pós-graduação em Zootecnia/UFRGS, Depto. de Plantas Forrageiras e Agrometeorologia, Caixa Postal 776, CEP: 91501 -970, \\ Porto Alegre, RS \\ ${ }^{3}$ Departamento de Plantas Forrageiras e Agrometeorologia da UFRGS. \\ ${ }^{4}$ Departamento de Zootecnia da UFPR.
}

RESUMO - Com objetivo de avaliar o comportamento de pastejo de novilhos de corte, foi desenvolvido um experimento em pastagem de azevém anual (Lolium multiflorum Lam) e aveia-preta (Avena strigosa Schreb) submetida a quatro alturas de manejo $(10,20,30$ e $40 \mathrm{~cm})$. Adotou-se o delineamento de blocos completos casualizados, com três repetições. O registro dos dados foi realizado durante o período diurno, por observação visual, em três datas de avaliação: duas no estádio vegetativo e uma no estádio reprodutivo. Avaliaram-se os tempos de pastejo, de ruminação e de outras atividades; o número e o tempo de duração das refeições; e o número e o tempo de duração dos intervalos de refeições. Com o aumento da altura do pasto, os animais reduziram o tempo de pastejo e o tempo de duração da refeição, mas aumentaram o tempo de ruminação. O tempo gasto em outras atividades, o número de refeições e a duração e o número de intervalos não diferiram entre as alturas impostas. O comportamento de pastejo dos animais é influenciado pela altura do pasto.

Palavras-chave: altura do pasto, bovinos, processo de pastejo

\section{Patterns in the use of time by steers in mixtures of Italian ryegrass (Lolium multiflorum Lam.) and black oat (Avena strigosa Schreb)}

\begin{abstract}
Aiming to assess the steer grazing behavior, an experiment was carried out with pastures composed by italian ryegrass (Lolium multiflorum Lam.) and black oat (Avena Strigosa Schreb) submitted to different sward heights (10, 20, 30, and $40 \mathrm{~cm}$ ). The sward heights were distributed in an experimental randomized block design with three replicates. Data was recorded by visual assessment, from sunrise until sundown, in three evaluation dates, two in the vegetative stage and one in the reproductive stage. The evaluated variables were grazing time, rumination time, idling time, number and length of meals, and number and length of meals intervals. Results indicated that with increasing sward height the animals reduced grazing time and the meal length as well, however, the ruminating time increased. The variables such as idling time, number of meals and number/length of intervals were not influenced by the sward surface height. The results showed changes in the animal grazing behavior due to the variations in sward height management.
\end{abstract}

Key Words: grazing process, steers, sward surface height

\section{Introdução}

O ecossistema de pastagens é caracterizado por uma série de inter-relações, como a interface planta-animal, regida por relações de causa e efeito, em que diferentes estruturas de pasto determinam padrões distintos de comportamento e desempenho animal (Carvalho, 1997). Nesse sentido, a oferta de estruturas de plantas adequadas nas pastagens é necessária para obtenção dos nutrientes exigidos pelo animal com vistas à facilitação da colheita de forragem, pelo aumento de sua velocidade de ingestão (Carvalho et al., 2005).

Assim, no estudo do consumo de forragem, deve-se considerar a escala de tempo, pois os princípios que o regulam são diferentes (Ungar, 1996; Laca \& Dement, 1992). A curto prazo, na escala de minutos a horas de pastejo, o consumo de forragem é associado à estrutura e acessibilidade do pasto e à sua abundância e qualidade, enquanto, a longo prazo, a resposta funcional é denominada consumo diário e determinada em escalas de dias a semanas e são 
considerados fatores fisiológicos e metabólicos (Laca \& Dement, 1992). Carvalho et al. (2005) propuseram um modelo empírico no qual o controle do consumo fosse enfocado em sua dinâmica dentro das refeições e entre refeições e o consumo a longo prazo seria um produto cumulativo da ingestão obtida em cada uma das refeições realizadas durante o dia; esse consumo seria diretamente associado ao controle da ingestão a curto prazo.

Quando somadas as refeições e suas respectivas durações ao longo do dia, obtém-se o tempo de pastejo diário (Carvalho \& Moraes, 2005), indicativo das condições de oferta de pasto. Neste sentido, as atividades dos animais são excludentes, ou seja, o aumento ou a redução no tempo de pastejo ocasiona alterações proporcionais no tempo disponível para a realização de atividades como ruminação, descanso, socialização, entre outras (Carvalho et al., 2001).

Com objetivo de descrever o comportamento de pastejo de bovinos em pastagem de azevém anual e aveia-preta nos estádios vegetativo e reprodutivo, foram impostas diferentes intensidades de pastejo, representadas por alturas de manejo, visando criar diversos ambientes de alimentação e estruturas de pasto. Investigou-se a hipótese de que as estruturas de pasto criadas determinariam padrões de comportamento distintos, ou seja, que o animal seria capaz de modificar suas estratégias de forrageamento em resposta a variações na altura do pasto.

\section{Material e Métodos}

O estudo foi realizado na Fazenda do Espinilho, pertencente à Agropecuária Cerro Coroado Ltda., situada no município de Tupanciretã, região do Planalto Médio do estado do Rio Grande do Sul, na região geográfica designada pela latitude $29^{\circ} 03^{\prime} 10^{\prime \prime}$ sul e longitude 5350'44" oeste, a $465 \mathrm{~m}$ de altitude, no período de julho a novembro de 2005. O solo da área experimental é classificado como Latossolo Vermelho Distroférrico (Embrapa, 1999) com condições de relevo suave ondulado (Streck et al., 2002). O clima da região é subtropical úmido (Cfa), conforme classificação climática de Köppen.

A área experimental tem sido conduzida em sistema de integração lavoura-pecuária desde 2001. No verão, a área foi cultivada com soja e, no inverno, em 4/5/2005, com aveia-preta (Avena strigosa Schreb.), $100 \mathrm{~kg} / \mathrm{ha}$, e azevém anual (Lolium multiflorum Lam.), $25 \mathrm{~kg} / \mathrm{ha}$, em plantio direto. A adubação no plantio foi feita com aplicação de superfosfato simples (300 kg/ha) e, no dia 8/6/2005, com aplicação de nitrogênio $(\mathrm{N})$ em cobertura, na dose de $45 \mathrm{~kg} / \mathrm{ha}$, na forma de uréia.
A área experimental foi composta de 22,5 ha e subdividida em 12 piquetes com áreas ajustadas de acordo com a taxa de lotação necessária para atingir e manter as alturas de manejo do pasto em $10,20,30$ e $40 \mathrm{~cm}$, mantidas constantes por meio de pastejo contínuo com taxa de lotação variável (Mott \& Lucas, 1952). O delineamento experimental adotado foi o de blocos completos casualizados, com três repetições.

Três bovinos de corte machos, provenientes de cruzamento industrial, oriundos do plantel da propriedade, com massa corporal média de $260 \mathrm{~kg}$ e aproximadamente 1 ano de idade foram submetidos às avaliações em cada unidade experimental. O pastejo iniciou-se em 5/7/2005 - quando o pasto atingiu, em média, $19 \mathrm{~cm}$ de altura e $900 \mathrm{~kg} / \mathrm{ha}$ de matéria seca (MS) de massa de forragem - e se estendeu até 13/11/2005, totalizando 131 dias de pastejo. As avaliações de comportamento em pastejo foram realizadas em três datas, 7/9/2005, 9/10/2005 e 30/10/2005, de modo que as duas primeiras coincidiram com o estádio vegetativo e a terceira, com o estádio reprodutivo.

As observações dos padrões de uso do tempo pelos animais foram realizadas no período diurno, por observação direta, por meio da visualização dos animais do início da manhã até o entardecer (aproximadamente das 6 h às 20 h). As avaliações foram realizadas simultaneamente nos três animais avaliadores de cada piquete registrando-se as atividades de cada animal, identificados a campo pelas suas diferenças morfológicas individuais (pelagem, tamanho, cor, etc.) e por brincos numerados.

As atividades foram monitoradas por meio de amostragem em intervalos representativos do comportamento (Penning $\&$ Rutter, 2004), registrando-se a atividade de maior ocorrência ao final de cada intervalo de 10 minutos e procedendo-se à classificação dos tempos em pastejo, ruminação e outras atividades.

A atividade de pastejo foi caracterizada pelo período no qual o animal se manteve envolvido nas atividades de procura, apreensão, manipulação e mastigação da forragem. O período de ruminação correspondeu ao tempo destinado pelo animal à mastigação do conteúdo ruminal previamente ingerido $\mathrm{e}$ foi identificado por movimentos mandibulares de elevada regularidade, com ausência de movimentos de apreensão. $\mathrm{O}$ tempo destinado a outras atividades correspondeu ao período em atividades fisiológicas, sociais, de descanso e vigilância, entre outras, ou seja, todas não enquadradas nos tempos de pastejo e de ruminação. Os valores médios, expressos em minutos, dos três animais avaliadores foram registrados comos tempos de pastejo, de ruminação e de outras atividades.

O número de refeições, o tempo de duração da refeição, o número de intervalos de refeições e o intervalo de refeições 
foram obtidos por meio do controle das atividades dos animais (Penning \& Rutter, 2004). Por definição, refeição é considerada uma longa seqüência de pastejo. Quando interrompida por vários minutos por qualquer outra atividade, a refeição anterior se define e a próxima é iniciada tão logo o animal realize nova seqüência (Carvalho \& Moraes, 2005). Neste trabalho, uma refeição foi caracterizada como uma seqüência de pastejo com no mínimo duas observações sucessivas de 10 minutos (20 minutos) na atividade de pastejo. A interrupção do pastejo por qualquer outra atividade, também por um período mínimo de 20 minutos, caracterizou o término da refeição e início do intervalo de refeições.

A equipe de trabalho, previamente treinada, foi formada por três observadores por bloco, totalizando nove indivíduos - posicionados fora das unidades experimentais e utilizando binóculos - para evitar interferência no comportamento normal dos animais em pastejo.

A altura do pasto foi monitorada utilizando-se bastão graduado (sward stick - Barthram, 1985), cujo marcador em acrílico transparente corre por uma régua e marca a distância entre o topo da superfície do pasto (lâmina foliar mais elevada) e a superfície do solo. Os registros de altura do pasto foram realizados nos dias 8 e 29/9/2005 e 29/10/2005. Os pontos de amostragem foram definidos de forma aleatória, de modo a totalizar cem leituras por unidade experimental.

A massa de forragem disponível foi obtida por corte com tesoura, rente ao solo, em área delimitada por um quadro de $0,25 \mathrm{~m}^{2}$, em cinco pontos amostrados por unidade experimental, obtidos de forma aleatória nas datas supracitadas. As amostras cortadas eram colocadas em saco de papel e secas em estufa de ventilação forçada a $65^{\circ} \mathrm{C}$ até peso constante, para determinação do teor de matéria seca (MS). A oferta de forragem (OF) foi determinada como a fração entre a forragem disponível e a carga animal média em cada data de avaliação de comportamento e expressa em $\mathrm{kg} / \mathrm{ha}$ de MS/kg de PV/dia (Sollenberg et al., 2005).

A proporção dos componentes estruturais do pasto foi realizada por meio da separação das frações lâmina foliar, colmo + bainha, inflorescência e material senescente de cada amostra coletada. Os componentes foram separados, acondicionados em sacos de papel, isoladamente, e mantidos em estufa até atingirem peso constante, quando foram pesados. As ofertas dos componentes do pasto foram expressas do mesmo modo que a oferta de forragem.

Os dados foram submetidos à análise de variância e ao teste F a 5\% de significância. Quando detectadas diferenças entre as alturas $(\mathrm{P}<0,05)$, as médias foram comparadas pelo teste $\mathrm{t}$ (Student) com mesmo nível de significância, utilizando-se o procedimento Mixed do pacote estatístico SAS, versão 8.2 (SAS, 2001). Foram realizadas análises de regressão até terceira ordem, conforme o modelo: $\hat{Y} \mathrm{ij}=\beta 0$ + b1 Ai + b2 Ai 2 + b3 Ai3 + $\gamma(\mathrm{i}, \mathrm{j})+\varepsilon(\mathrm{i}, \mathrm{j})$, em que: $\hat{\mathrm{Y}}=$ variável dependente; $\beta 0=$ intercepto da regressão; $A=$ variável independente; $\mathrm{b} 1$ = coeficiente linear de regressão da variável Y em relação à variável independente; b2 = coeficiente quadrático de regressão da variável Y relacionada à variável independente; b3 = coeficiente cúbico de regressão da variável Y em relação à variável independente; $\gamma=$ desvios da regressão e $\varepsilon=$ erro aleatório residual.

$\mathrm{O}$ modelo matemático geral referente à análise das variáveis estudadas foi representado por: $Y_{i k j}=\mu+T_{i}+\beta_{k}$ $+(\mathrm{T} \beta)_{\mathrm{ik}}+\mathrm{E}_{\mathrm{j}}+(\mathrm{TE})_{\mathrm{ij}}+\varepsilon_{\mathrm{ikj}}$, em que $\mathrm{Y}_{\mathrm{ikj}}=$ variáveis dependentes; $\mu=$ média de todas as observações; $\mathrm{T}_{\mathrm{i}}=$ efeito das alturas do pasto; $\beta_{\mathrm{k}}=$ efeito do k-ésimo bloco; $(\mathrm{T} \beta)_{\mathrm{ik}}=$ efeito da interação alturas do pasto $\times$ blocos (erro a); $E_{j}=$ efeito do j-ésimo estádio fenológico do pasto; $(\mathrm{TP})_{\mathrm{ij}}=$ interação alturas do pasto $\times$ estádios fenológicos; e $\varepsilon_{\mathrm{ikj}}=$ erro experimental residual (erro b). Também procedeu-se à análise de regresão com o auxílio do software estatístico Sigma Plot 2004 v.9.0 para Windows.

\section{Resultados e Discussão}

As alturas médias obtidas pelo uso de lotações variáveis foram próximas das previamente estabelecidas, conforme as alturas propostas no estádio vegetativo, criando diferentes estruturas de pasto sobre as quais os animais pudessem interagir. Possibilitou-se, assim, a ocorrência de variações em suas estratégias de forrageamento, tanto na busca quanto na aquisição da forragem, tendo em vista a criação de diversos ambientes de alimentação. Na média, as alturas obtidas no estádio vegetativo foram de 8,$7 ; 20,2$; 35,3 e 44,1 $\pm 1,7 \mathrm{~cm}$, respectivamente, para as alturas de 10 , 20,30 e $40 \mathrm{~cm}$. As alturas verificadas no estádio reprodutivo se ajustaram de forma menos precisa às alturas pretendidas, em virtude da maior dificuldade na manutenção da altura do pasto neste estádio de desenvolvimento das plantas na pastagem. As alturas observadas no estádio reprodutivo foram de 22, $1 ; 34,9 ; 31,3$ e 38,5 $\pm 1,7 \mathrm{~cm}$.

Não houve interação alturas de manejo $\times$ estádios fenológicos do pasto $(\mathrm{P}>0,05)$ para a massa de forragem e para a oferta de forragem. Considerando os dois estádios, a massa de forragem e a oferta de forragem variaram, respectivamente, entre 2.112 e $4.961 \pm 84,1 \mathrm{~kg} / \mathrm{ha}$ de $\mathrm{MS}$ e 1,7 e $14,4 \pm 0,8 \mathrm{~kg} / \mathrm{hade} \mathrm{MS} / \mathrm{kg}$ de PV/dia na maior e na menor intensidade de pastejo. A massa de forragem aumentou de 

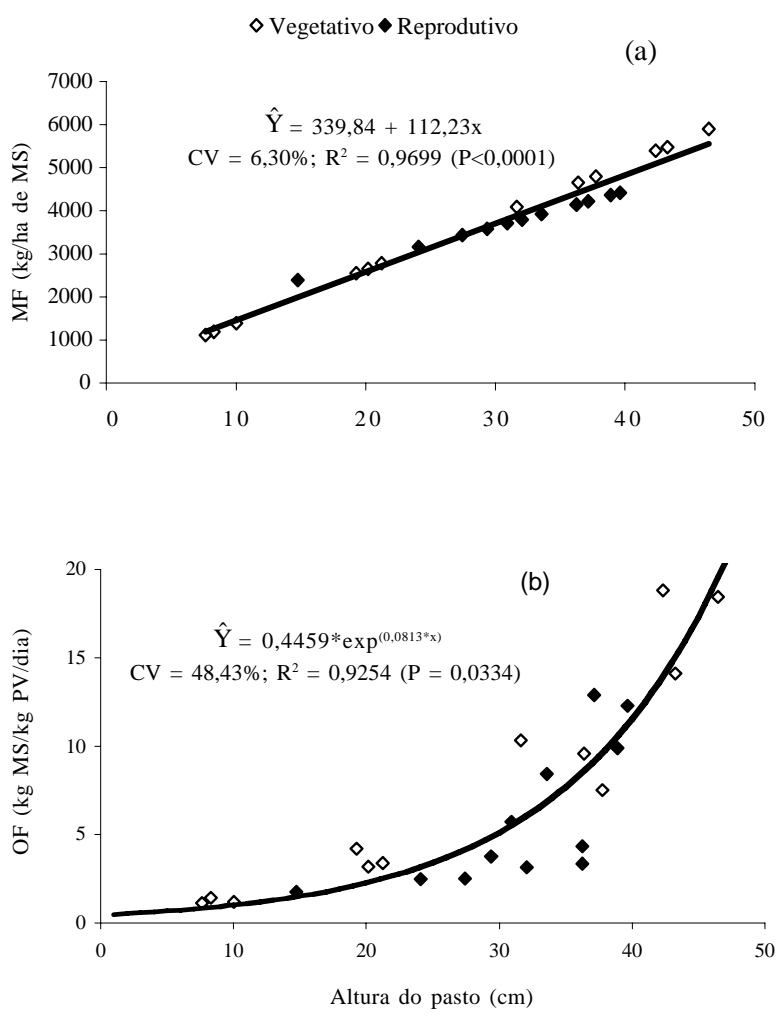

Figura 1 - Massa de forragem (MF; a) e oferta de forragem (OF; b) em diversas alturas de manejo em pastagem de azevém anual e aveia-preta nos dois estádios avaliados.

forma linear e a oferta de forragem, de forma exponencial, com o aumento da altura do pasto, o que confirma a criação de diversos ambientes de alimentação (Figura 1). Palhano et al. (2002), da mesma forma, observaram aumento linear na massa de forragem com o aumento da altura do pasto, como consequiência do efeito da altura de manejo sobre a massa de forragem.

Observou-se efeito $(\mathrm{P}=0,0065)$ da interação altura de manejo $\times$ estádio fenológico do pasto sobre a massa de lâminas foliares. Esse efeito se ajustou ao modelo de regressão linear no estádio vegetativo (Figura 2), revelando aumento da participação desse componente com o aumento da altura do pasto. No estádio reprodutivo, a massa de lâminas foliares, média de 185,67 $\pm 33,51 \mathrm{~kg} / \mathrm{ha} \mathrm{de}$ MS, não se ajustou a nenhum modelo de regressão, pois, em situações de baixa intensidade de pastejo, à medida que os perfilhos amadurecem, não produzem mais folhas novas (Pontes et al., 2004).

A massa de colmos + bainhas foi influenciada pela interação altura $\times$ estádio fenológico e ajustou-se ao modelo de regressão linear no estádio vegetativo ( $\hat{Y}=-325,13+$ $\left.71,49 x ; r^{2}=0,99 ; \mathrm{P}<0,0001 ; \mathrm{CV}=6,41 \%\right)$. No estádio reprodutivo, esta variável não se ajustou aos modelos de regressão e apresentou média de 1.300,64 $\pm 64,12 \mathrm{~kg} / \mathrm{ha}$ de

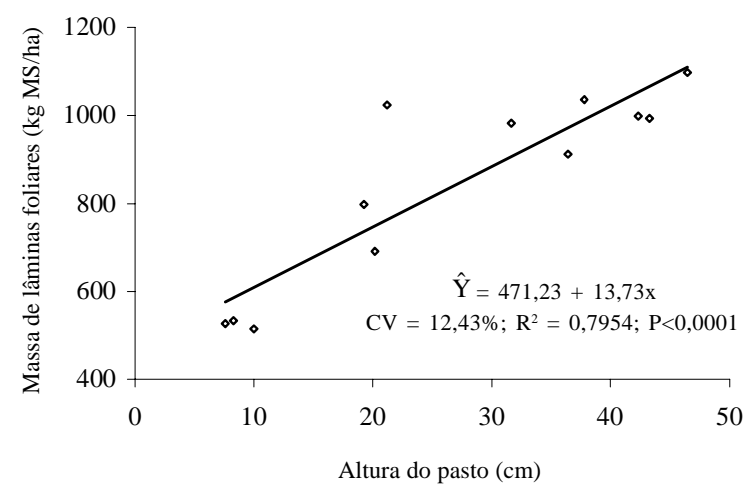

Figura 2 - Relação entre massa de lâmina foliar e altura do pasto em pastagem de azevém anual e aveia-preta no estádio vegetativo.

MS. Situações de pastejo moderado, com menores freqüências e intensidades de desfolha, geraram maior altura e, conseqüentemente, maior participação de bainhas e colmos. As massas de material senescente $(P=0,0003)$ e de inflorescências $(\mathrm{P}=0,0110)$ diferiram entre os estádios avaliados e aumentaram de 756 para $1.531 \pm 94,1 \mathrm{~kg} / \mathrm{ha} \mathrm{de}$ MS e de 291 para $759 \pm 91,9 \mathrm{~kg} / \mathrm{ha}$ de MS, respectivamente.

A interação altura $\times$ estádio teve efeito $(\mathrm{P}<0,0001)$ sobre a oferta de lâminas foliares, que aumentou de acordo com a altura do pasto no estádio vegetativo ( $\hat{\mathrm{Y}}=-0,17+$ $0,07 \mathrm{x} ; \mathrm{r}^{2}=0,86 ; \mathrm{P}<0,0001 ; \mathrm{CV}=24,48 \%$ ), enquanto, no estádio reprodutivo, apresentou média de $0,22 \pm 0,07 \mathrm{~kg} / \mathrm{ha}$ de MS/kg de PV/dia, não se ajustando a nenhum modelo de regressão. Aguinaga et al. (2006) também relataram aumento na oferta de lâminas foliares com o aumento da altura de manejo em pastagem de azevém anual e aveiapreta. As demais características, inflorescência ( $\hat{Y}=-0,70$ $\left.+0,05 \mathrm{x} ; \mathrm{r}^{2}=0,57 ; \mathrm{P}<0,0001 ; \mathrm{CV}=61,10 \%\right)$, colmo + bainha $\left(\hat{Y}=-2,34+0,17 x ; r^{2}=0,54, P<0,0001 ; C V=66,91 \%\right) e$ material senescente $\left(\hat{\mathrm{Y}}=-1,02+0,11 \mathrm{x} ; \mathrm{r}^{2}=0,36 ; \mathrm{P}=0,0018\right.$; $\mathrm{CV}=77,16 \%$ ), aumentaram de acordo com altura de manejo do pasto e com o aumento da massa de forragem. No entanto, não houve interação altura $\times$ estádio do pasto para essas variáveis. A oferta de colmo + bainha diminuiu de 3,7 para 1,9 $\pm 0,2 \mathrm{~kg} / \mathrm{ha} \mathrm{de} \mathrm{MS} / \mathrm{kg}$ de PV/dia do estádio vegetativo para o reprodutivo $(\mathrm{P}<0,0001)$, o que indica maior consumo de colmo + bainha no estádio reprodutivo, enquanto a oferta de material senescente aumentou de 1,6 para 2,7 $\pm 0,2 \mathrm{~kg} / \mathrm{ha}$ de $\mathrm{MS} / \mathrm{kg}$ de PV/dia $(\mathrm{P}<0,0001)$.

Com o aumento das alturas de manejo, verificou-se decréscimo no tempo destinado à atividade de pastejo $(\mathrm{P}=0,0208)$. Não houve interação altura $\times$ estádio fenológico do pasto $(\mathrm{P}>0,05)$. O maior tempo de pastejo observado na altura de $10 \mathrm{~cm}$ pode estar relacionado à menor altura do 
pasto e à baixa massa de forragem. O tempo em pastejo variou de 459 a $380 \pm 37,1$ minutos da menor para a maior altura de pasto. O aumento do tempo de pastejo é uma estratégia dos animais de compensar a diminuição da massa do bocado e aumentar o consumo de forragem em situações de baixa disponibilidade de forragem (Laca et al., 1992). Nesse sentido, o tempo de pastejo foi negativamente correlacionado à oferta de forragem $\left(\mathrm{r}^{2}=-0,53 ; \mathrm{P}=0,0008\right)$ (Figura 3). Sarmento (2003) descreveu tendência similar, ou seja, em pastos mantidos a $10 \mathrm{~cm}$ de altura, os animais despendem aproximadamente 1 hora a mais de pastejo em comparação ao tempo gasto em pastos de $40 \mathrm{~cm}$.

O tempo de pastejo diferiu entre os estádios avaliados $(\mathrm{P}=0,0042)$ e aumentou de 390 para $460 \pm 20,6$ minutos do estádio vegetativo para o estádio reprodutivo, possivelmente em virtude do aumento da proporção dos componentes material senescente e inflorescência na estrutura do pasto e da significativa redução da quantidade de massa de lâminas foliares, o que pode reduzir a qualidade e aumentar a seletividade, tornando necessário aumentar o tempo da atividade de pastejo. $\mathrm{O}$ aumento do tempo de pastejo com a diminuição da oferta de forragem é uma resposta clássica (Carvalho, 1997) e também foi verificado por Pinto et al. (2007) e Barbosa et al. (2007) em pesquisas com novilhos e cordeiros, respectivamente.

A atividade de ruminação foi influenciada $(\mathrm{P}<0,05)$ pela interação altura $\times$ estádio fenológico do pasto. No estádio vegetativo, es s a variável aumentou de acordo com a altura do pasto $\left(\hat{\mathrm{Y}}=101,5+1,22 \mathrm{x} ; \mathrm{r}^{2}=0,69 ; \mathrm{P}=0,0443\right.$; $\mathrm{CV}=18,79 \%$ ), o que confirma as observações de Silveira (2001) de que a altura de manejo influencia as atividades de pastejo e ruminação. De acordo com esse autor, à medida que a oferta de forragem aumentou, os animais reduziram o tempo de pastejo e aumentaram o tempo de ruminação. No estádio reprodutivo, o tempo de pastejo (média de $192,2 \pm 6,3$ minutos) não se ajustou aos modelos de regressão testados.

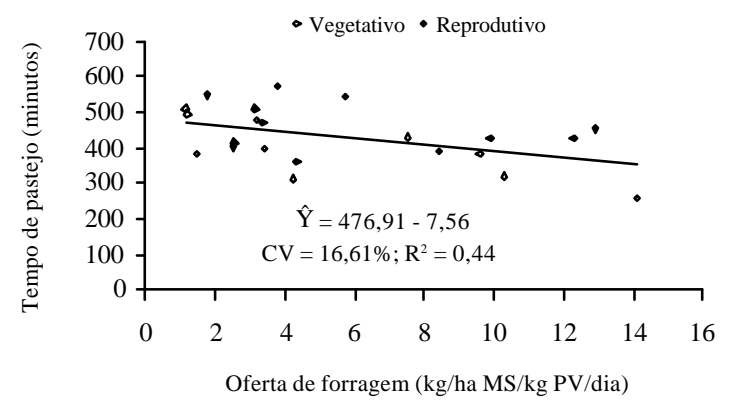

Figura 3 - Relação entre tempo de pastejo e oferta de forragem em pastagem de azevém anual e aveia-preta nos estádios vegetativo e reprodutivo.
O tempo destinado pelos animais a outras atividades não diferiu $(\mathrm{P}>0,05)$ entre as alturas de manejo avaliadas. Resposta semelhante foi relatada por Silveira (2001), que concluiu que esta é uma variável comportamental que os animais pouco alteram, qualquer que sejam as condições de alimentação, pois nela incluem atividades independentes do aspecto nutricional, como atividades de socialização, de termorregulação, entre outros.

A distribuição das atividades diárias dos animais em pastejo (Figura 4) comprova que, em ambos os estádios avaliados, o pico da atividade de pastejo ocorreu ao entardecer, no período das 17 às 19 h, o que resultou em refeições com mais longa duração ao final da tarde. Segundo Carvalho (1997), os animais intensificam suas estratégias de ingestão de nutrientes de acordo com os teores de carboidratos não-fibrosos e matéria seca nas plantas no período ainda com luminosidade do dia. No período entre o final da tarde e o início da noite, os bocados realizados pelos animais contêm mais nutrientes que os bocados coletados em outros horários, o que significa que o pastejo ao entardecer é eficiente e favorável se considerada a proporção nutriente ingerido/nutriente despendido.

O tempo de ruminação indicou percentual menor das atividades no estádio vegetativo em comparação ao estádio reprodutivo, comprovando que a dieta obtida pelos animais neste estádio foide menor qualidade.

(a) Vegetativo

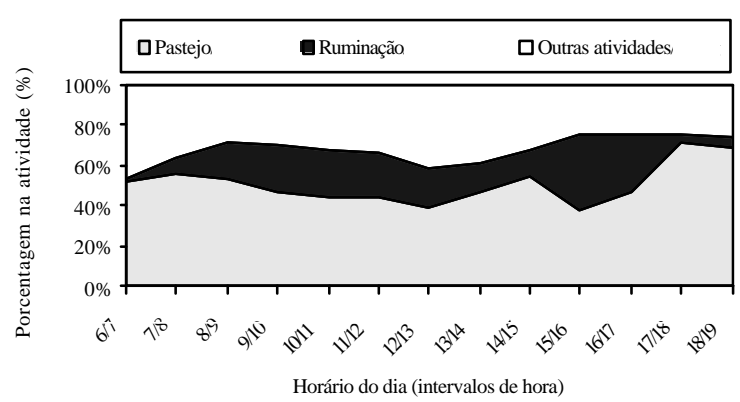

(b) Reprodutivo

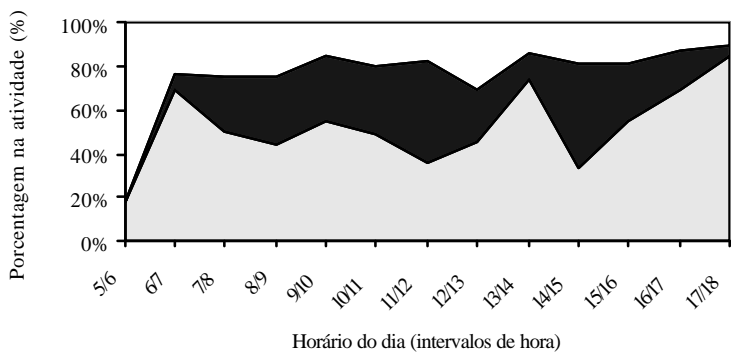

Figura 4 - Distribuição percentual das atividades diurnas de novilhos em pastagem de azevém anual e aveia-preta nos estádios vegetativo (a) e reprodutivo (b). 
Observou-se interação altura do pasto $\times$ estádio fenológico $(\mathrm{P}=0,0209)$ para o tempo de duração da refeição. No estádio vegetativo, o tempo de duração da refeição reduziu linearmente com o aumento da altura do pasto $\left(\hat{\mathrm{Y}}=92,25-0,83 \mathrm{x} ; \mathrm{r}^{2}=0,52 ; \mathrm{P}=0,0302 ; \mathrm{CV}=22,53 \%\right)$, enquanto, no estádio reprodutivo, essa variável não se adequou aos modelos de regressão. A média de tempo de duração da refeição foi de 84,24 \pm 5,91 minutos e está de acordo com o proposto por Carvalho \& Moraes (2005) de que, em situações de abundância de forragem, o número de cada refeição é maior e a duração, menor. Nessa situação, verifica-se elevada seletividade de forragem e o animal responde diretamente à estrutura do pasto e pode colher dieta de elevada qualidade com maior rapidez, conseqüentemente, o estímulo para interrupção da refeição, associado ao possível aumento de sinais saciedade, é mais rápido.

O tempo de duração da refeição apresentou correlação negativa com a massa de lâminas foliares $\left(\mathrm{r}^{2}=-0,56 ; \mathrm{P}=0,0006\right)$ (Figura 5). A maior oferta desse componente nos pastos com maiores alturas ocasionou redução do tempo de duração da refeição, pois os animais atingem o ponto de saciedade em menor espaço de tempo (Carvalho \& Moraes, 2005).

As alturas de pastejo não afetaram $(\mathrm{P}>0,05)$ o número de refeições, cuja média foi de 6,04 $\pm 0,3$ refeições. Possivelmente, a menor quantidade de massa de forragem nos pastos com alturas mais baixas não permitiu alterações comportamentais a longo prazo. De acordo com Barbosa et al. (2007), a alteração do tempo de duração da refeição de animais em pastejo seria uma modificação comportamental decorrente de alterações na estrutura do pasto. Segundo os autores, isso representa menor custo para o animal em comparação às alterações no número de refeições. Conseqüentemente, alterações no número de refeições são observadas somente em situações de limitação da quantidade de forragem em oferta.

O tempo e o número de intervalos de refeições não teve efeito sobre as alturas de manejo $(\mathrm{P}>0,05)$, cujos valores médios foram de 66,07 $\pm 3,7$ minutos e 5,05 $\pm 0,3$ intervalos, respectivamente. Silveira (2001) verificou que os valores médios do tempo por intervalo não diferiram, porém observou que, nos pastos com maiores alturas e mais alta quantidade de forragem disponível, a quantidade de intervalos de refeições e o tempo destinado a outras atividades são maiores.

\section{Conclusões}

Em situações de baixa disponibilidade de forragem, os animais apresentam estratégias alimentares compensatórias. Nessas situações, aumentam o tempo de pastejo e o tempo de duração da refeição, diminuindo o tempo de

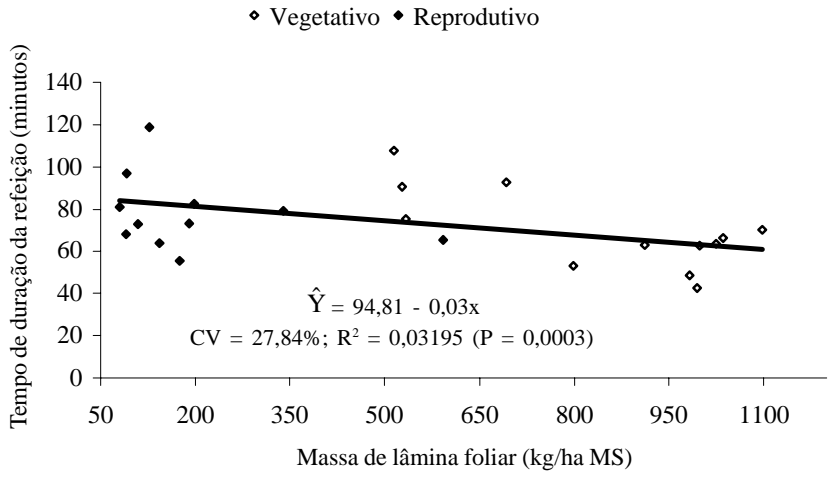

Figura 5 - Relação entre o tempo de duração da refeição e a massa de lâmina foliar em pastagem de azevém anual e aveia-preta nos estádios vegetativo e reprodutivo.

ruminação. Do mesmo modo, modificam seu padrão de comportamento, aumentando o tempo de pastejo de acordo com as alterações no pasto decorrentes de sua fenologia.

\section{Agradecimento}

Aos membros do Grupo de Pesquisa em Ecologia do Pastejo, pelo apoio; à Agropecuária Cerro Coroado; e ao CNPq.

\section{Literatura Citada}

AGUINAGA, A.A.Q.; CARVALHO, P.C.F.; ANGHINONI, I. et al. Produção de novilhos superprecoces em pastagem de aveia e azevém submetida a diferentes alturas de manejo. Revista Brasileira de Zootecnia, v.35, n.4, p.1765-1773, 2006 (supl).

BARBOSA, M.P.; CARVALHO, P.C.F.; CAUDURO, G.F. et al. Componentes do processo de pastejo de cordeiros em azevém (Lolium multiflorum Lam) sob diferentes intensidades e métodos. Archivos de Zootecnia, 2008. (no prelo).

BARTHRAM, G.T. Experimental techniques: the HFRO sward stick. Aberdeen: Hill Farming Research Organization/Biennial Report, 1985. p.29-30.

CARVALHO, P.C.F. A estrutura da pastagem e o comportamento ingestivo de ruminantes em pastejo. In: SIMPÓSIO SOBRE AVALIAÇÃO DE PASTAGENS COM ANIMAIS, 2., 1997, Maringá. Anais... Maringá: Universidade Estadual de Maringá, 1997. p.25-52.

CARVALHO, P.C.F.; GENRO, T.C.M.; GONÇALVES, E.N. et al. A estrutura do pasto como conceito de manejo: reflexos sobre o consumo e a produtividade. In: SIMPÓSIO DE VOLUMOSOS NA PRODUÇÃO DE RUMINANTES, 2., 2005, Jaboticabal. Anais... Jaboticabal: Unesp, 2005. p.107-124.

CARVAlHO, P.C.F.; MORAES, A. Comportamento ingestivo de ruminantes: bases para o manejo sustentável do pasto. In: MANEJO SUSTENTÁVEL EM PASTAGEM, 1., 2005, Maringá. Anais... Maringá, 2005. (CD-ROM).

CARVALHO, P.C.F.; PRACHE, S.; DAMASCENO, J.C.O. et al. Processo de pastejo: desafios da procura e apreensão da forragem pelo herbívoro. In: REUNIÃO ANUAL DA SOCIEDADE BRASILEIRA DE ZOOTECNIA, 36., 1999, Porto Alegre. Anais... Porto Alegre, 1999a. p.253-268. 
EMPRESA BRASILEIRA DE PESQUISA AGROPECUÁRIA EMBRAPA. Centro Nacional de Pesquisa de Solos. Sistema Brasileiro de Classificação de Solos. Rio de Janeiro: 1999. 412p.

LACA, E.A.; DEMMENT, M.W. Modelling intake of a grazing ruminant in a heterogeneous environment. In: INTERNATIONAL SYMPOSIUM ON VEGETATTION HERBIVORE RELATHIONSHIPS, 1992, New York. Proceedings... New York: Academic Press, 1992. p. 57-76.

LACA, E.A.; UNGAR, E.D.; SELIGMAN, N. et al. Effects of sward height and bulk density on bite dimensions of cattle grazing homogeneous sward. Grass and Forage Science, v.47, n.1, p.91-102, 1992.

MOTT, G.O.; LUCAS H.L. The design, conduct, and interpretation of grazing trials on cultivated and improved pastures. In: INTERNATIONAL GRASSLAND CONGRESS, 6., 1952, Pensylvania. Proceedings... Pensylvania, 1952. p.1380-1385.

PALHANO, A.L.S.; CARVALHO, P.C.F.; GANCHAR, A.P.S. et al. Estratégias de pastejo de novilhas holandesas em pastagem de capim mombaça. Ciência e Cultura, v.31, p.21-31, 2002.

PENNING, P.D.; RUTTER, S.M. Ingestive behavior. In: THE BRITISH GRASSLAND SOCIETY (Ed). Herbage intake handbook. 2.ed. Reading: British, 2004. p.151-175.

PINTO, C.E.; CARVALHO, P.C.F.; FRIZZO, A. et al. Comportamento ingestivo de novilhos em uma pastagem nativa do Rio Grande do Sul. Revista Brasileira de Zootecnia, v.36, n.2, p.319$327,2007$.
PONTES, L.S.; CARVALHO, P.C.F.; NABINGER, C. et al. Fluxo de biomassa em pastagem de azevém anual (Lolium multiflorum Lam.) manejada em diferentes alturas. Revista Brasileira de Zootecnia, v.33, n.3, p.529-537, 2004.

SARMENTO, D.O.L. Comportamento ingestivo de bovinos em pastagens de capim Marandu submetidos a regimes de lotação contínua. Piracicaba: Escola Superior de Agricultura "Luiz de Queiroz", 2003. 76p. Dissertação (Mestrado em Agronomia) Escola Superior de Agricultura "Luiz de Queiroz", 2003.

STATISTICAL ANALYSIS SYSTEM - SAS. Statistical analysis system user's guide. Version 8.2 Cary: SAS Institute, 2001. (CD-ROM).

SILVEIRA, E.O. Comportamento ingestivo e produção de cordeiros em pastagem de azevém anual (Lolium multiflorum Lam.) manejada em diferentes alturas. Porto Alegre: Universidade Federal do Rio Grande do Sul, 2001. 154p. Dissertação (Mestrado em Zootecnia) - Universidade Federal do Rio Grande do Sul, 2001.

SOLLENBERG, L.E.; MOORE, J.E.; ALLEN, V.G. et al. Reporting forage allowance in grazing experiments. Crop Science, v.45, n.3, p.896-900, 2005.

STRECK, E.V; KÄMPF, N.; DALMOLIN, R.S.D. et al. Principais classes de solo identificadas no Rio Grande do Sul. In: STRECK, E.V.; KÄMPF, N.; DALMOLIN, R.S.D. et al. (Eds). Solos do Rio Grande do Sul. 1.ed. Porto Alegre: Emater/RS; UFRGS, 2002. p.23-50.

UNGAR, E.D. Ingestive behavior. In: HODGSON, J.; ILLUS, A. (Eds). The ecology and management of grazing system. Wallingford: CAB International, 1996. p.185-218. 